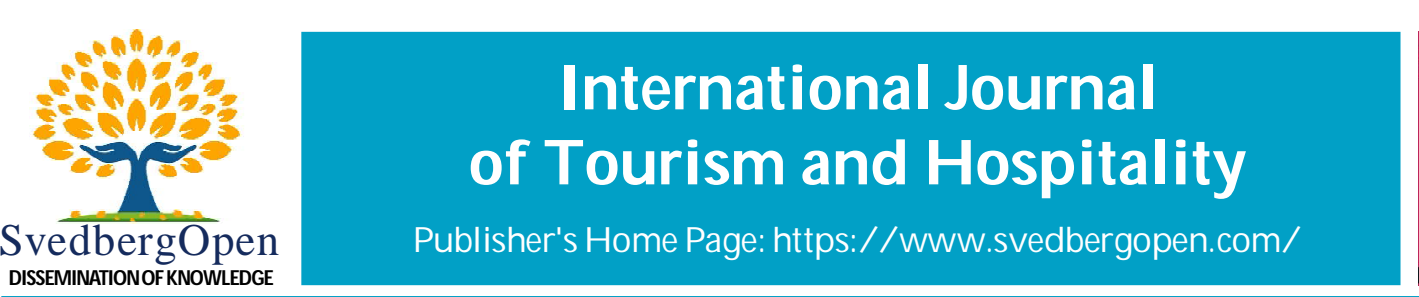

Research Paper

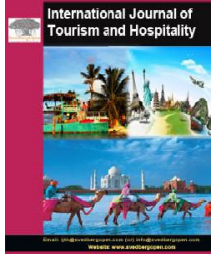

\title{
Assessing the Efficacy of Online Learning Among Hospitality and Tourism Management Students in Bulacan State University-Hagonoy Campus
}

\author{
Virginia Natividad-Franco ${ }^{1 *}$ and Maybelle N. Dela Cruz ${ }^{2}$ \\ ${ }^{1}$ Ph.D., Bulacan State University, City of Malolos, Bulacan, Philippines. E-mail: virginia.franco@bulsu.edu.ph \\ ${ }^{2}$ Ph.D., Bulacan State University, City of Malolos, Bulacan, Philippines. E-mail: maybelle.delacruz@bulsu.edu.ph
}

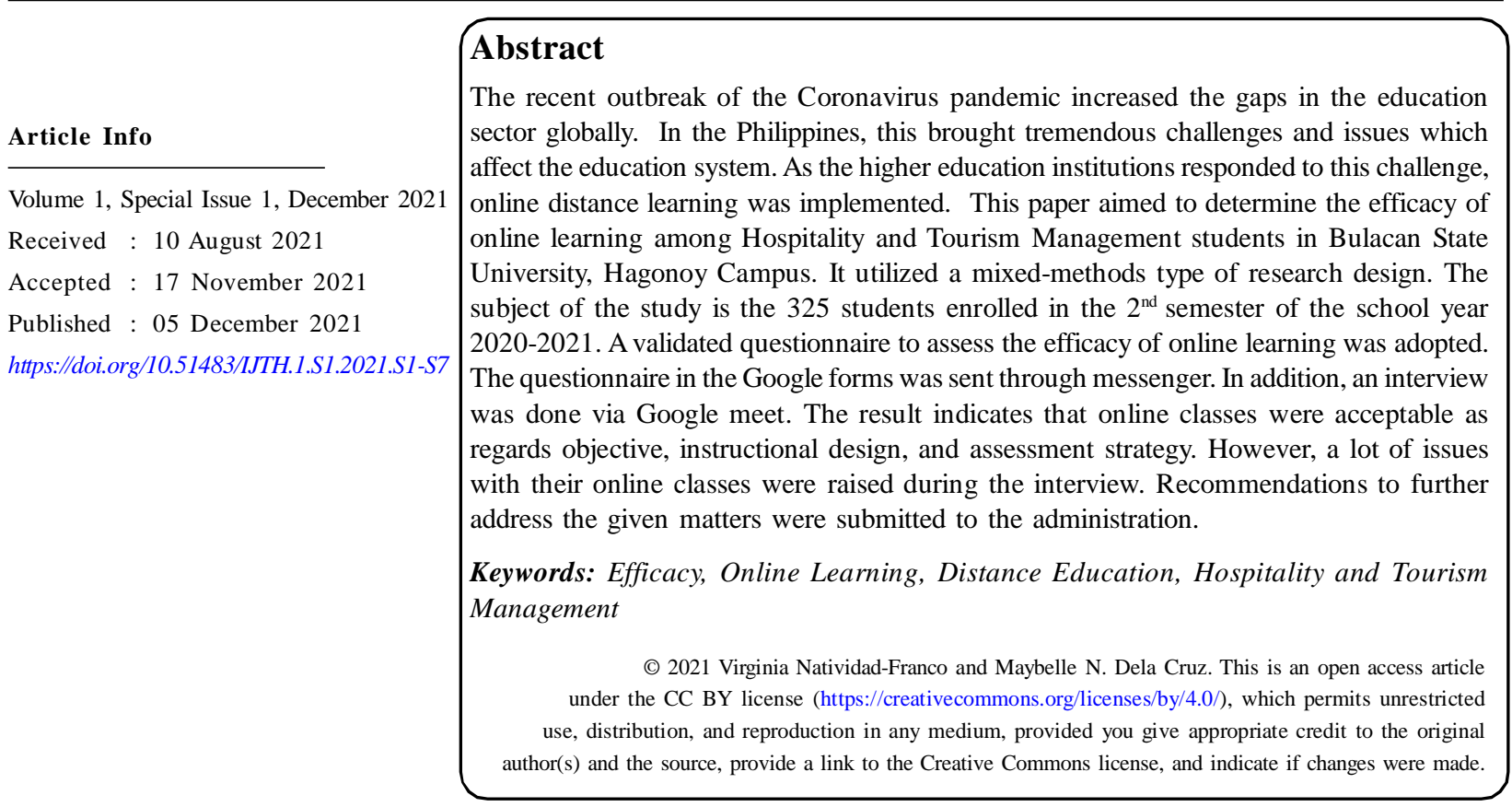

\section{Introduction}

Covid-19 was declared a global public health emergency of international concern on January 30, 2020 and a pandemic on 11th March 2020 by the World Health Organization (Cucinotta and Vanelli, 2020). This recent outbreak increased the gaps in the education sector globally. Indeed, like many other aspects of everyday life, Covid-19 has had a severe impact on students, instructors, and educational organizations around the globe (Mailizar et al., 2020). The pandemic caused schools, colleges, and universities worldwide to shut down their campuses so that students could follow social distancing measures (Toquero, 2020).

These tremendous challenges and issues affect the education system in the Philippines. Thus, the higher education institutions in the country responded to this challenge through online learning. Bulacan State University is one of the leading universities in the region that adhered to these changes. However, turning quickly from an environment of conventional education to distance and virtual learning could not happen overnight. This rapid transformation is linked

\footnotetext{
* Corresponding author: Virginia N atividad-Franco, Ph.D., Bulacan State U niversity, City of M alolos, Bulacan, Philippines.
} E-mail: virginia.franco@bulsu.edu.ph 
to various obstacles and challenges (Crawford et al., 2020). Sinceno one knows when this pandemic will end entirely, educational institutions across the globe decided to use the already available technical resources to create online learning material for students of all academic fields (Kaur, 2020).

The use of information technology has a significant role in the implementation of distance learning amid the coronavirus pandemic. The learning process can run well with the existence of information technology that has developed rapidly. It includes e-learning, Google class, WhatsApp, zoom, and other information media and internet networks connecting lecturers and students. The learning process can be appropriately run as it should be, although amid the coronavirus pandemic Covid-19.

Online learning is a form of distance education, where learning occurs partially or entirely over the Internet. It is claimed that any learning arrangement with substantial elements of online learning is considered as online learning (Nguyen, 2015). Today's online learning offers rich educational resources in multiple media and the capability to support both real-time and asynchronous communication between instructors and learners and among different learners (Means et al., 2009).

Online learning can mean a learning experience entirely online (such as a course delivered or a degree obtained at a distance). It also combines online engagement with some face-to-face activity (often referred to as blended learning); it can be synchronous, asynchronous, or a combination of both. Likewise, Bates (2005) viewed online learning as an increasingly popular method used by institutions in various countries to provide opportunities and meet the needs of a growing and increasingly diverse student population (Rumble and Latchem, 2004).

However, online learning can be effective in digitally advanced countries (Basilaia and Kvavadze, 2020). According to the study of Bahasoan et al. (2020), the online learning system carried out during the COVID-19 pandemic is effective and inefficient. Effectively implemented because of the conditions that require online study and inefficient because the costs incurred more when compared with offline lectures. Various studies have been carried out regarding online learning while pandemic COVID 19 occurs. Pakpahan and Fitriani (2020) conducted a study entitled Analysis of the Utilization of Information Technology in Distance Learning in the Middle of Corona Covid-19 Pandemic Virus.

During online learning, assignments are often given via applications. Students are given tasks to complete. Then, teachers grade them and provide feedback as a form of evaluation for students. Online learning is not primarily about materials distributed through the internet and students completing the assignments and submitting them through applications and social media platforms. Therefore, during online learning, educators should plan, implement, and evaluate learning the same way as during offline learning.

Sun and Chen (2016) found that one of the fundamental challenges in online learning is to develop a sense of community in the online environment. Therefore, promoting social presence, interaction and collaboration are significant in the implementation of online learning.

Hundreds of institutions provide online courses, but two problems exist. First, from a macro viewpoint, very little is established regarding the effects and efficacy of online education (McPherson and Bacow, 2015). Second, the capacity to successfully teach digitally is likely to differ based on the wide range of learning goals that guide our instructional and educational priorities (Liguori and Winkler, 2020).

Also, Rohman et al. (2020) showed that most students had negative perceptions of online learning. Eventhough they agreed that online learning was the right solution during the Covid-19 pandemic, the online learning which was implemented without proper planning resulted in the absence of easiness, involvement, and effectiveness of online learning. Most students complained about the learning processes dominated by assignments and unstable and high cost of internet connection. Careful university management, designer, and lecturers are needed to create beneficial online learning for the students. Markova et al. (2017) stated that educators and students encounter specific barriers that affect the overall quality of distance learning. Contrary to Wallace (2020), he concluded that high-ability students were well served online delivery.

Innovative delivery technologies have expanded the traditional classroom setting to distance or online learning. Whether the characteristics of successful students in the conventional classroom setting transfer to success in distance classes are uncertain (Zahed-Babelan and Moenikia, 2010). Thus, instructional designers created online courses for simple conversions of their equivalent face-to-face counterparts. Online courses tend to build on traditional views of learning where the primary goal is to transfer information from the instructor to the student. It is accomplished by providing students with access to information and expecting them to demonstrate their learning on an exam (Johnson and Aragon, 2003). 
The initial design of an online class provides a prompt for instructors to examine deliberate learning assessment strategies. An effective online instructor orchestrates several interactive learning and assessment activities to guide and document the learning process. Learning activities and assessment are connected very closely in well-designed online courses. The first step in making connections is to identify the desired course objectives. The syllabus should clearly state course learning objectives, learning methods, and how learning assessments will be used.

Typically, instructors use Bloom's (1956) taxonomy to write objectives for learning gains in three domains, cognitive, affective, and psychomotor. In higher education, the higher-order skills of application, analysis, synthesis, and evaluation are preferred for course learning objectives within the cognitive domain. In designing assessments, instructors need to state clearly their expectations for honesty and the consequences of breaking course and university policies (Sewell et al., 2010).

Furthermore, understanding various instructional practices changed significantly from a tell, show, and do model to an interactive and engaging approach.Online learning provides learners with an opportunity and flexibility for learning at any time and in any place (Auyeung, 2004).

Similarly, this study assessed the efficacy of online learning, which aims to answer the following research questions: (1) What is the efficacy of online learning in terms of objective, instructional design, and assessment strategy as perceived by students? (2) What do students raised as issues and challenges during the implementation of the online classes?

\section{Methodology}

The study utilized the mixed-methods type of research. Mixed-methods research integrates qualitative and quantitative data within a single study (Halcomb and Hickman, 2015). Mixed methods take advantage of the strengths of both qualitative and quantitative procedures while improving on their weaknesses to provide an integrated, comprehensive understanding of the topic under investigation (Scammon et al., 2013).

The subject of the study is the 325 Hospitality and Tourism Management students enrolled in the $2^{\text {nd }}$ semester of S.Y. 2020-2021 at the Bulacan State University-Hagonoy Campus, whom the researchers randomly selected.

It utilized a validated instrument in assessing the efficacy of online learning with a reliability test result of Cronbach alpha of .910. The survey questionnaire in Google form was sent via Messenger. Selected respondents were askedfor permission for their willingness to be interviewed, and the discussion was done through Google meet.

\section{Results and Discussion}

This study intended to assess the efficacy of online learning among Hospitality and Tourism Management students in Bulacan State University-Hagonoy Campus.

The efficacy of online learning as perceived by students are presented on the following tables:

Table 1: Efficacy of Online Learning in Terms of Objective

\begin{tabular}{|l|c|c|}
\hline \multicolumn{1}{|c|}{ Indicator } & Mean & VI \\
\hline The online learning objectives/outcomes are measurable and clearly stated. & 3.58 & Agree \\
\hline $\begin{array}{l}\text { The online learning objectives/outcomes are aligned with Bloom's Taxonomy of } \\
\text { Educational Objectives. }\end{array}$ & 3.53 & Agree \\
\hline $\begin{array}{l}\text { Online learning includes opportunities to practice, apply, analyze, or synthesize } \\
\text { new information, consisting of worked or practice exercises, labs, or case studies. }\end{array}$ & 3.47 & Agree \\
\hline Weighted Mean & $\mathbf{3 . 5 2}$ & Agree \\
\hline
\end{tabular}

As can be glean from the table, the efficacy of online learning in terms of objectives got a weighted mean of 3.52 with a verbal interpretation of Agree. The result indicates that the majority of the respondents agreed that the objectives of online learning are achieved.

Online learning aims to deliver the teaching-learning process among students online without jeopardizing its quality, aligning with the university's goal of providing relevant quality and accessible education. 
Table 2 presents the assessment of students on online learning regarding instructional designs. The online classes have a variety of instructions that promotes learning outcomes. This indicator got a mean of 3.58. It states that students have agreed that the present online classes in the campus utilized various instructions. Regarding the precise delivery of instructions, the mean is 3.54 , indicating that students agreed on this premise.

Table 2: Efficacy of Online Learning in Terms of Instructional Design

\begin{tabular}{|c|c|c|}
\hline Indicator & Mean & VI \\
\hline $\begin{array}{l}\text { The online learning classes include a variety of interactions that promote learning } \\
\text { outcomes. (Interactions may have student-to-content, student-to-student, } \\
\text { student-to-instructor, student-to-other activities to promote learning outcomes.) }\end{array}$ & 3.58 & Agree \\
\hline Activity instructions deliver clear student expectations and match course objectives. & 3.54 & Agree \\
\hline $\begin{array}{l}\text { Activities/interactions promote learning based on Bloom's Taxonomy } \\
\text { of educational objectives. }\end{array}$ & 3.47 & Agree \\
\hline There are rubrics used to define expectations for activities/interactions. & 3.79 & Agree \\
\hline Weighted Mean & 3.59 & Agree \\
\hline
\end{tabular}

Furthermore, the activities/interactions promoted were based on Bloom's Taxonomy of Educational Objectives got a mean of 3.47. It indicates that the instructors ensure that their lessons are aligned to the educational objectives in online learning. Likewise, the students' activities are adequately assessed through a defined rubrics with a mean of 3.79. The assessment of students in terms of instructional strategies garnered a weighted mean of 3.59, providing a verbal interpretation of agree.

This result indicates that online learning as regards instructional design is attained. It is similar to the impact of the study of Liguori and Winkler (2020), wherein the capacity to successfully teach digitally is likely to differ based on the wide range of learning goals that guide our instructional and educational students to understand the lessons.

Table 3 presents the efficacy of online learning in terms of assessment strategy. The respondents rate the first indicator, assessment(s), match learning objectives with a mean of 3.66. It means that the assessment given by instructors on the campus corresponds to the expected output of the study. It also shows that clear directions were provided in the assessment. This got a mean of 3.66. Also, the grading policy was clearly defined the assessment, which got a mean of 3.77. Likewise, the rubrics for the evaluation was define and got a mean of 3.75. The next indicator is that self-assessment is incorporated, obtained a mean of 3.55. Lastly, teacher grading/feedback protocol is clearly stated, with all assessments obtained a mean of 3.71. Students believed that the assessment strategy regarding online learning is achieved and successfully implemented by teachers from these indicators. Sewell et al. (2010) stated that instructors need to clearly communicate their expectations for honesty and the consequences of breaking course and university policies in designing assessments. Also, the capacity to successfully teach digitally is likely to differ based on the wide range of learning

Table 3: Efficacy of Online Learning in Terms of Assessment Strategy

\begin{tabular}{|c|c|c|}
\hline Indicator & Mean & VI \\
\hline Assessment(s) match learning objectives. & 3.66 & Agree \\
\hline Clear directions for assessment(s) are provided. & 3.66 & Agree \\
\hline Grading policy is clearly defined for the assessment(s) & 3.77 & Agree \\
\hline Rubrics define assessment expectations/grading (when applicable). & 3.75 & Agree \\
\hline Self-assessments are incorporated. & 3.55 & Agree \\
\hline Teacher grading/feedback protocol is clearly stated with all assessments. & 3.71 & Agree \\
\hline Weighted Mean & 3.68 & Agree \\
\hline
\end{tabular}


goals that guide our instructional and educational priorities (Liguori and Winkler, 2020). The goals and objectives of the instructional design were shown and provided the priorities.

The researchers interviewed selected Hospitality and Tourism Management students regarding the issues and challenges they encountered in implementing the online classes. The researchers explained the purpose and aims of the study. They are further informed about the confidentiality of their anonymity, and the information is solely for research purposes.

Table 4: Issues and Challenges Experienced by Students on the Implementation of Online Learning

\begin{tabular}{|ll|}
\hline \multicolumn{2}{|l}{ Themes } \\
\hline 1. & Weak internet connection \\
\hline 2. & Skills are not enhanced (bartending, baking, etc.) \\
\hline $3 . \quad$ Dissemination of Information and announcement \\
\hline $4 . \quad$ Conducting Research is hard \\
\hline $5 . \quad$ Teachers don't know all the students in an online class \\
\hline $6 . \quad$ Students become lazy \\
\hline 7. & Financial problem (need to buy load every class) \\
\hline
\end{tabular}

During the interview, the following themes were crafted. The first one raised was the weak internet connection. Many of them experienced slow or bad internet. Knowing that some of them come from island places wherein internet connection is through mobile data only. Because of weak internet links, they couldn't understand the discussion well because of weak internet links, and downloading graphics, presentations, and videos is complicated.

The next issue was the enhancement of their skills. Since they belong to skilled people, they are expected to be knowledgeable and skillful in their field. Some students stated how they could be good at bartending and baking if they don't have the types of equipment in their houses. Though their instructors demonstrate it during their classes, the lack of equipment hinders them from enhancing their skills.

Another issue that these group of students agreed upon is the dissemination of information or announcement. Some of them told the researchers that not all announcements about their classes, submissions, and the like reach them; thus, they couldn't make it to submit on time.

Some of them are enrolled in the Research subject; having it online made them so hard to understand and finished every detail of their papers. Since research needs to have reviewed some literature and studies, it's hard for them to look for sample thesis because they are not allowed to come to school and go to the library. Data gathering is quite tricky because not all the respective respondents tend to answer the survey questionnaire. This problem made some of them not finish the data gathering, which resulted in an unfinished paper.

One more issue experienced by students is the fact that teachers don't know all their students. Perhaps, not all of them are opening cameras during the discussion, unlike face-to-face that you will see whom you are talking to.

Another thing, online learning made some students lazy, that instead of doing the activities during classes, they tend to do it some other time. Lastly, most of them encountered financial problems as regards attending online classes. Just counting the number of enrolled subjects, that's the number of hours the students need to attend classes. Each attendance means to buy some load for their mobile phones to have data.

These are the issues and challenges experienced by some hospitality and tourism management students enrolled in Bulacan State University-Hagonoy Campus.

\section{Conclusion}

Online learning is a form of distance education, where learning occurs partially or entirely over the Internet. The Hospitality and Tourism Management students stated that the efficacy of online learning in terms of objectives, 
instructional designs, and assessment strategies agreed that they all achieved these purposes in their study. The survey questionnaire results adhered to these statements and were even supported during the interview.

However, a lot of issues were raised as regards their experienced. The challenges they encountered made the implementation a bit weak that needs to be addressed. Hence the school administrators were informed about the result of the survey, and further recommendations were suggested.

\section{References}

Auyeung, L. H. (2004). Building a collaborative online learning community: a case study in Hong Kong. Journal of Educational Computing Research, 31(2), 119-136.

Bahasoan, A.N., Ayuandiani, W., Mukhram, M. and Rahmat, A. (2020). Effectiveness of Online Learning in Pandemic Covid-19. International Journal of Science, Technology \& Management, 1(2), 100-106.

Basilaia, G. and Kvavadze, D. (2020). Transition to Online Education in Schools During a Sars-Cov-2 Coronavirus (Covid-19) Pandemic in Georgia. Pedagogical Research, 5(4).

Bates, A.W. (2005). Technology, e-Learning and Distance Education (2nd ed.). New York: RoutledgeFalmer.

Bloom, B.S. (1956). Taxonomy of Educational Objectives, Handbook 1: Cognitive Domain. New York: Addison Wesley Publishing Company.

Crawford, J., Butler-Henderson, K., Rudolph, J. and Glowatz, M. (2020). COVID-19: 20 countries' higher education IntraPeriod Digital Pedagogy Responses. Journal of Applied Teaching and Learning (JALT), 3(1).

Cucinotta, D. and Vanelli, M. (2020). WHO Declares Covid-19 a Pandemic. Acta Bio-Medica: AteneiParmensis, 91(1), 157-160.

Halcomb, E.J. and Hickman, L. (2015). Mixed Methods Research.

Johnson, S.D. and Aragon, S.R. (2003). An Instructional Strategy Framework For Online Learning Environments. New Directions for Adult and Continuing Education, 2003(100), 31-43.

Kaur, G. (2020). Digital Life: Boon or Bane in Teaching Sector on Covid-19. CLIO an Annual Interdisciplinary Journal of History, 6(6), 416-427.

Liguori, E. and Winkler, C. (2020). From offline to online: Challenges and opportunities for entrepreneurship education following the COVID-19 pandemic. Entrepreneurship Education and Pedagogy, 3(4), 346-351.

Mailizar, Almanthari, A., Maulina, S. and Bruce, S. (2020). Secondary School Mathematics Teachers' Views on E-Learning Implementation Barriers During the Covid-19 Pandemic: The Case of Indonesia. Eurasia Journal of Mathematics, Science and Technology Education, 16(7), em1860.

Markova, T., Glazkova, I., and Zaborova, E. (2017). Quality Issues of Online Distance Learning. Procedia - Social and Behavioral Sciences, 237( 2017), 685-691.

McPherson, M.S. and Bacow, L.S. (2015). Online Higher Education: Beyond the Hype Cycle. Journal of Economic Perspectives, 29(4), 135-54.

Nguyen, T. (2015). The Effectiveness of Online Learning: Beyond No Significant Difference and Future Horizons. MERLOT Journal of Online Learning and Teaching, 11(2), 309-319.

Pakpahan, Roida, and Fitriani, Yuni (2020). Analysis of the Utilization of Information Technology in Distance Learning in the Middle of Corona COVID Pandemic Virus-19. Bina SaranaInformatika University.

Rohman, M., Marji, D.A.S., Sugandi, R.M. and Nurhadi, D. (2020). Online Learning in Higher Education During Covid-19 Pandemic: Students' Perceptions. Journal of Talent Development and Excellence, 12(2s), 3644-3651.

Rumble, G. and Latchem, C. (2004). OrganIsational Models For Open And Distance Learning. Policy For Open And Distance Learning. In H. Perraton and H. Lentell (Eds.), Policy for Open and Distance Learning (pp. 117-140). London: Routledge Falmer.

Scammon, D.L., Tomoaia-Cotisel, A., Day, R.L., Day, J., Kim, J., Waitzman, N.J., Farrell, T.W. and Magill, M.K. (2013) Connecting the Dots and Merging Meaning: Using Mixed Methods to Study Primary Care Delivery Transformation. Health Services Research, 48, 2181-2207. 
Sewell, J., Frith, K.H. and Colvin, M.M. (2010). Online Assessment Strategies: A Primer. Journal of Online Learning and Teaching, 6(1), 297-305. Retrieved from http://jolt.merlot.org/vol6no1/ sewell_0310.pdf

Sun, A. and Chen, X. (2016). Online Education And Its Effective Practice: A Research Review. Journal of Information Technology Education: Research, 15, 157-190.

Toquero, C.M. (2020). Challenges and Opportunities for Higher Education Amid the Covid-19 Pandemic: The Philippine Context. Pedagogical Research, 5(4).

Wallace, P.E. (2020). Achievement Predictors For A Computer-applications Module Delivered Online. Retrieved from: http://jise.org/Volume11/n1-2/JISEv11n1-2p13.pdfFeng, Gao. (2011). Design for social-based reflection in health behavior change

Zahed-Babelana, A. and Moenikia, M. (2010). The Role of Emotional Intelligence in Predicting Students' Academic Achievement in Distance Education System. Procedia Social and Behavioral Sciences, 2, 1158-1163. 